\title{
Physico-chemical attributes and correlation among grain quality traits of some exotic aromatic rice lines
}

\author{
S. Seraj, L. Hassan, S. N. Begum ${ }^{1}$, M. M. Sarker \\ Department of Genetics and Plant Breeding, Bangladesh Agricultural University, Mymensingh-2202, Bangladesh and \\ ${ }^{1}$ Plant Breeding Division, Bangladesh Institute of Nuclear Agriculture (BINA), Mymensingh, Bangladesh, Email: \\ seraj_bau@yahoo.com
}

\begin{abstract}
Forty three rice genotypes were used to evaluate their aroma detection through sensory test. Aroma was detected by $1.7 \% \mathrm{KOH}$ as a sensory test. Thirteen rice genotypes were detected having strong aroma; ten had moderate aroma; fifteen had slight aroma and five had no aroma. In case of grain shape study, 37 genotypes were evaluated as slender and six as medium. In this study, grain aroma had significant and positive association with grain length width ratio; significant and negative association with grain width, significant and negative association with gelatinization temperature, and significant and negative association with grain length. Gelatinization temperature had significant and negative correlation with grain length, significant and negative association with grain length width ratio, significant and positive association with grain width. Grain length had significant and negative correlation with grain width; significant and positive correlation with length width ratio. Grain width had significant and negative correlation with length width ratio. Finally, it can be concluded that among 43 genotypes Basmati370,CT19541-13-3-1-2P1P,PSBRC18,PSB-RC2(IR32809-26-3-3),IR64,IR50,2001059-TR2151-6-1-1,IR64-P401,IR72-P204 were found good grain quality traits having higher physico-chemical attributes. These elite lines could be readily used in breeding programmes to improve grain quality traits.
\end{abstract}

Keywords: Aromatic Rice, Physicochemical Properties, Aroma, Grain Quality Traits, Oryza sativa L.

\section{Introduction}

Rice (Oryza sativa L.) is the most important crop at the global level, as it is the staple food for more than two fifths (2.4 billion) of the world's population (Latha et al., 2004). The total cropped area of Bangladesh is 33422 thousand acres of which 26130 thousand acres are used for rice cultivation and the production of rice is 28931 thousand metric tons (BBS, 2012). It provides about $75 \%$ of the total calories and $55 \%$ of the proteins in the average daily diet of the people of Bangladesh (Bhuiyan et al., 2002). In Bangladesh, more than 150 crops are grown. Among these crops, rice occupies about $70 \%$ of the total cultivated area, of which aromatic rice is cultivated roughly in less than $10 \%$ land (Sarker, 2002).

Aromatic rice is closely related to social and cultural heritage of Bangladesh and it is consumed during different social and religious festivals such as weddings, entertaining guests etc. by all classes of people in addition to the demand of the top class hotels (Shangi et al., 2010). Aromatic rice is preferred by consumers all over the world due to its flavor and palatability. It is generally used to prepare dishes such as 'polau', 'biriani', 'paish', 'khir', 'jarda', 'khoi' etc. which are served on special occasions (Jorhi Behera, 2007).

Demand for aromatic rice in last ten years has been increased to a greater extent for both internal consumption and export (Singh et al., 2000 and Das \& Bagai, 2000). Bangladesh imports around 50 thousand tons of aromatic rice each year from neighboring countries (Bayes, 2003). Islam et al.,(1996) observed that the yield of aromatic rice is lower (1.5-2.0 t/ha) but its higher price and low cost of cultivation generated higher profit margins compared to other varieties grown in the area(Mia et al.,2010).

Grain quality of rice plays an important role in consumer acceptability since rice is mainly consumed as whole grain especially in Asia. (Juliano and Duff, 1991) concluded that grain quality is second after yield as the major breeding objectives. The quality in rice is considered from the view point of milling quality, grain size, shape, appearance and cooking characteristics determined to increase the acceptability to the consumer (Dela Cruz and Khush, 2000) and to evaluate physical and physico-chemical traits of aromatic rice genotypes. 


\section{Materials and Methods}

The details of different materials used and methodology followed during the research period are discussed in this chapter.

Material used: Forty three rice genotypes were used in the present experiment with diverse origin. These genotypes were collected from INGER (International Network for Genetic Evaluation of Rice), IRRI, Philippines.

Location and season: This part of the experiment was conducted at the experimental field and Biotechnology laboratory of Plant Breeding Division Bangladesh Institute of Nuclear Agriculture (BINA), Mymensingh from mid-July 2012 to mid-February 2013.

Phenotyping for grain quality traits: Mature seeds from each genotype were harvested individually. The seeds were oven dried. Then the seeds were dehulled for evaluation of the following phenotypic characters in the Biotechnology Laboratory, Plant Breeding Division, BINA, Mymensingh.

\section{Data collection}

Grain length and grain width (GL and GW) : Grain length (grain size) and grain width of 10 random sample of whole rice grains from each 43 genotypes measured manually and then average length and width were used as the length and width (in $\mathrm{mm}$ ) in this study.

Grain length width ratio (GLWR): Grain length width ratio (grain shape) was obtained from the above measurements. Grain length width ratio, GLWR = GL (grain length) / GW (grain width).

Aroma: Forty three freshly harvested milled rice grains from each of genotypes were crushed or powdered. The powder was taken in conical flax. About $10 \mathrm{ml} 1.7 \% \mathrm{KOH}$ solution was added to each of the conical flax and the flaxes were covered immediately with aluminum foil and left at room temperature for about $1 \mathrm{~h}$ (Fig.1). The flaxes were then opened one by one and the content of each flax was immediately smelt by experienced persons.

Gelatinization temperature (GT): Gelatinization temperature was assessed using standard alkali digestion and spreading scores (Little et al., 1958). Six whole grains from each of the genotypes were placed in plastic Petridish containing $10 \mathrm{ml} 1.7 \% \mathrm{KOH}$ (Fig. 2). The arrangements of grains were in such a way that they were not in contact with each other. Petri dishes were covered and incubated for twenty three hrs at $30^{\circ} \mathrm{C}$. Scoring was done on the basis of visual appearance and disintegration of the endosperm.

\section{Results and Discussion}

The results obtained from different experiments of the present study have been presented and described under the following headings.

Classification of grain quality traits of $\mathbf{4 3}$ rice genotypes: Market quality of aromatic rice is determined largely by the physical appearance of the kernel. The physical appearance varies with respect to its shape and size. Forty three rice genotypes were subjected to various grain quality analyses. The phenotypic analysis for grain quality traits was performed after harvesting the grains. Aroma was scored under four classes (no aroma $=1$, slight aroma $=2$, moderate aroma $=3$ and strong aroma =4), gelatinization temperature by alkali digestion test and grain shape and size were classified by standard scale. 


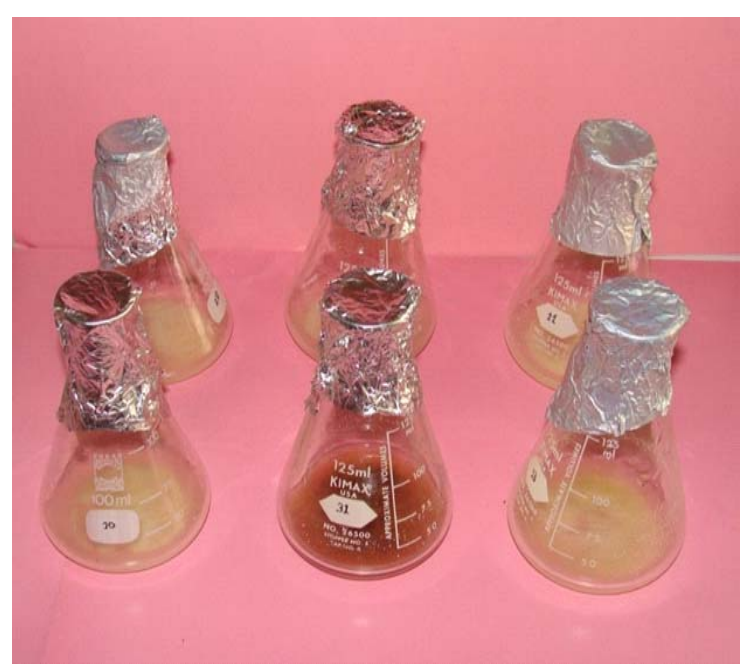

Fig. 1. Detection of aroma using $\mathrm{KOH}$

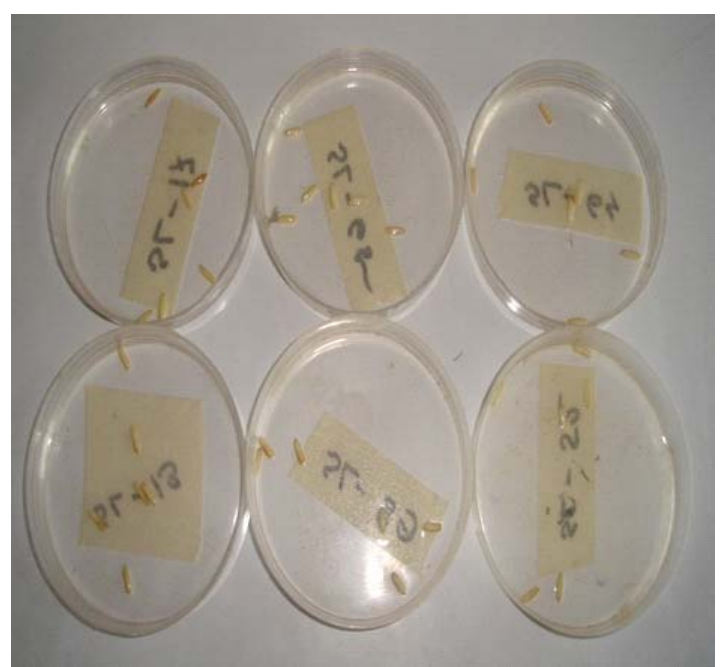

Fig. 2. Alkali digestion of rice grains

Different grain quality traits of the $\mathbf{4 3}$ rice genotypes: From the result (Table 1), revealed that there is variation among all the genotypes studied for different quality traits. It ranged from 1 to 4 for aroma score, 1 to 7 for alkali score, 5.9 to $8.0 \mathrm{~mm}$ for grain length, 1.6 to $2.5 \mathrm{~mm}$ for grain width and 2.3 to 4.7 for grain length-width ratio.

The result showed that maximum 21 genotypes had grain length between $6.65-7.75 \mathrm{~cm}$ and 5 genotypes had a grain length more than $7.5 \mathrm{~cm}$. Twenty four genotypes had higher grain length-width ratio over 3.0 $\mathrm{mm}$ and only two genotype had grain length-width ratio below $3.0 \mathrm{~mm}$. The result also showed that most of the genotypes have strong to moderate aroma. Only ten genotypes had slight aroma and three had no aroma at all. With respect to alkali spreading value, ten genotypes having a score of 1 to 2.Sarker et al., (1994) mentioned that preference for grain size and shape varies from one group of consumer to another. In general, long grains are preferred in the Indian subcontinent, but in Southeast Asia, the demand is for medium long rice. There is a high demand for long grain rice in the national market. Tomar and Nanda (1985) observed that slender kernel which was dominant over the medium and bold, whereas medium kernel was dominant over bold. Sharma (2002) mentioned that the aromatic cultivars possessed a slender shape compared with the medium-slender shape of non-aromatic cultivars. Bhattacharya (1989) and Siddiq (1992) suggested that intermediate to slightly high amylose content with intermediate gelatinization temperature is preferred in international market.

\section{Correlation among grain quality traits}

In this study, aroma had significant and positive association with grain length width ratio; significant and negative association with grain width, significant and negative association with gelatinization temperature, and not significant with grain length. Gelatinization temperature had non-significant and negative correlation with grain length, significant and negative association with grain length width ratio, significant and positive association with grain width. Grain length had significant and negative correlation with grain width; significant and positive correlation with length width ratio. Grain width had significant and negative correlation with length width ratio. This result is similar to the findings of Begum (2006). Chauhan (1998) also found similar result. In contrast, Tomar and Nanda (1985) did not find any association between kernel size and shape. It had significant negative association between grain width and grain length width ratio. It had significant positive correlation between grain length and grain width. Begum (2006) found highly significant and negative correlation between grain length and width. 
Table 1. Different grain quality traits of the 43 rice genotypes

\begin{tabular}{|c|c|c|c|c|c|}
\hline \multirow[b]{2}{*}{ Varieties } & \multicolumn{5}{|c|}{ Phenotypic data } \\
\hline & Aroma & $\begin{array}{c}\text { Alkali } \\
\text { digestion } \\
\text { score } \\
\end{array}$ & $\begin{array}{c}\text { Grain Length } \\
(\mathrm{mm}) \\
\text { (Grain size) }\end{array}$ & $\begin{array}{l}\text { Grain } \\
\text { wide } \\
(\mathrm{mm})\end{array}$ & \begin{tabular}{|c|} 
Len. Wide \\
Ratio(L/W) \\
(Grain shape)
\end{tabular} \\
\hline 2001059-TR2151-6-1-1 & 4 & 1 & 6.9 & 2 & 3.4 \\
\hline PSB RC2(IR32809-26-3-3) & 3 & 4 & 6.8 & 2 & 3.4 \\
\hline 2001027-TR2119-3-1-1 & 2 & 1 & 7.2 & 1.9 & 3.7 \\
\hline RI1812084-12-1-1 & 3 & 4 & 8 & 2 & 4 \\
\hline BASMATI370-P302 & 4 & 1 & 7.4 & 1.8 & 4.1 \\
\hline BASMATI370-P208 & 4 & 1 & 7.4 & 1.8 & 4.1 \\
\hline IR64-P401 & 4 & 1 & 7.3 & 2 & 3.6 \\
\hline IR72-P204 & 1 & 6 & 7.4 & 2.2 & 3.3 \\
\hline IR50-P303 & 3 & 5 & 6.4 & 2 & 3.2 \\
\hline IR64-P315 & 1 & 7 & 6.6 & 2.2 & 3 \\
\hline IR50-P104 & 2 & 5 & 5.9 & 2.5 & 2.3 \\
\hline RI1812084-96-1-1 & 2 & 4 & 6.9 & 2 & 3.4 \\
\hline UPR2729-15-1-1-1 & 3 & 3 & 6.8 & 2 & 3.4 \\
\hline PSB RC18(IR51672-62-2-1-1-2-3)-P101 & 4 & 2 & 7.6 & 1.6 & 4.7 \\
\hline BASMATI370-P109 & 4 & 1 & 7.4 & 1.8 & 4.1 \\
\hline PSB RC18(IR51672-62-2-1-1-2-3)-P212 & 2 & 7 & 7 & 2 & 3.5 \\
\hline IR03A480 & 4 & 1 & 7.1 & 1.9 & 3.7 \\
\hline PR33319-9-1-1-5-3-5-4-1 & 3 & 3 & 6.4 & 2 & 3.2 \\
\hline RI1812084-90-1-1 & 2 & 1 & 6.4 & 1.9 & 3.3 \\
\hline WAS169-B-B-4-2-4 & 2 & 2 & 6.9 & 2.2 & 3.1 \\
\hline IR50-P214 & 3 & 3 & 7 & 2.1 & 3.3 \\
\hline WAS169-B-B-4-2-3 & 3 & 3 & 7.1 & 2.1 & 3.4 \\
\hline IR72-P404 & 2 & 6 & 7 & 1.9 & 3.6 \\
\hline RI1812084-25-1-1 & 1 & 6 & 6.9 & 2.4 & 2.9 \\
\hline IR09A101 & 1 & 7 & 6.6 & 2.2 & 3 \\
\hline TOX1768-3-1-1-103-3 & 4 & 1 & 6.9 & 2 & 3.4 \\
\hline PLANT SUGANDH DHAN 17 & 3 & 4 & 6.8 & 2 & 3.4 \\
\hline PSB RC18(IR51672-62-2-1-1-2-3)-P406 & 2 & 1 & 7.2 & 1.9 & 3.7 \\
\hline WAS169-B-B-4-2-9 & 3 & 4 & 8 & 2 & 4 \\
\hline CT19541-13-3-1-2P-1P & 2 & 1 & 7.6 & 1.9 & 4 \\
\hline IR04A346 & 4 & 3 & 7 & 2 & 3.5 \\
\hline CT19541-13-3-1-2P-2P & 4 & 1 & 7.3 & 2 & 3.6 \\
\hline RI1812084-95-1-1 & 2 & 3 & 7.7 & 2.1 & 3.6 \\
\hline CT19541-13-3-1-2P-3P & 1 & 6 & 7.4 & 2.2 & 3.3 \\
\hline IR68058-64-1-2 & 3 & 5 & 6.4 & 2 & 3.2 \\
\hline IR07A166 & 1 & 7 & 6.6 & 2.2 & 3 \\
\hline PSB RC18(IR51672-62-2-1-1-2-3)-P306 & 2 & 5 & 5.9 & 2.5 & 2.3 \\
\hline 99020-TR1987-3-1-1 & 2 & 4 & 6.9 & 2 & 3.4 \\
\hline BASMATI370-P409 & 4 & 1 & 7.4 & 1.8 & 4.1 \\
\hline PSB RC64(IR59552-21-3-2-2)-P312 & 4 & 2 & 7.6 & 1.6 & 4.7 \\
\hline SHIRODI & 2 & 5 & 7.3 & 2.1 & 3.4 \\
\hline PSB RC64(IR59552-21-3-2-2)-P211 & 4 & 1 & 7.1 & 1.9 & 3.7 \\
\hline BRRI dhan-38 & 2 & 3 & 6.7 & 2.1 & 3.6 \\
\hline Mean & 2.6818 & 3.3863 & 7.0273 & 2.0181 & 3.50 \\
\hline Range & $1-4$ & $1-7$ & $5.9-8.0$ & $1.6-2.5$ & $2.3-47$ \\
\hline SD & 1.0395 & 2.102 & 0.4642 & 0.1837 & 0.4755 \\
\hline
\end{tabular}


Table 2. Correlations among aroma, gelatinization temperature, grain length, grain width and grain length width ratio of the Forty three rice genotypes

\begin{tabular}{|l|l|l|l|c|}
\hline Traits & \multicolumn{1}{|c|}{$\begin{array}{c}\text { Gelatinization } \\
\text { temperature } \\
(\mathrm{ASS})\end{array}$} & $\begin{array}{c}\text { Grain length } \\
(\mathrm{mm})\end{array}$ & $\begin{array}{c}\text { Grain width } \\
(\mathrm{mm})\end{array}$ & $\begin{array}{c}\text { Grain length width } \\
\text { ratio }\end{array}$ \\
\hline Aroma & $-0.71339^{\star}$ & $0.291066^{*}$ & $-0.63606^{\star}$ & $0.566978^{\star}$ \\
\hline $\begin{array}{l}\text { Gelatinization } \\
\text { temperature (ASS) }\end{array}$ & & $-0.33211^{\star}$ & $0.576116^{\star}$ & $-0.53062^{\star}$ \\
\hline Grain length & & & $-0.5439^{\star}$ & $0.804596^{\star}$ \\
\hline Grain width & & & & $-0.90567^{*}$ \\
\hline
\end{tabular}

$*=5 \%$ level of significant

\section{Conclusion}

The paper has concentrated on the physico-chemical attributes and correlation among grain quality traits with consumer preferences of traditionally cultivated scented and Basmati rice varieties. Among the varieties studied traditionally cultivated aromatic rice Basmati 370, CT 19541-13-3-1, PSB-RC-18, PSBRC-2,IR-64,IR-50, 2001059-TR-151-6-1-1,IR-72 performances best both physico-chemical attributes and correlation among grain quality traits. Correlation analysis always helps the consumers to select better rice varieties for their consumption and use. It is also emphasized that the training and recruiting the sensory expert panel are important in the process of sensory and correlation analysis (Lefebvre et al., 2010). The present study revealed that some of the exotic aromatic rice varieties have potential for consumer's preferences and it could be used for breeding programmes and biotechnological research for the improvement of valuable grain quality traits.

\section{Acknowledgements}

This research was supported by grant from Biotechnology laboratory of Plant Breeding Division, Bangladesh Institute of Nuclear Agriculture (BINA), Mymensingh.

\section{References}

Bayes, A. 2003. Research for rich rice. The Daily Star. July 30, 2003.

BBS (Bangladesh Bureau of Statistics). 2012. Statistical Pocket Book of Bangladesh. Ministry of Planning, Government of the People's Republic of Bangladesh: 61-65.

Begum, S.N. 2006. Development of Basmati-derived rice lines for grain quality and resistance to bacterial blight. Ph. D. Disscatation. Bangladesh Agricultural University, Mymensingh, Bangladesh. . $215 \mathrm{p}$

Bhttacharya, R.K. 1989. Need for widening the scope of rice breeding in India for the purpose of table rice. Oryza, 26: 117-122.

Bhuiyan, S.I. and Karim, A.N.M.R. 2002. Rice production in Bangladesh: an overview. Bangladesh Rice Research Institute. Joydebpur, Dhaka. pp. 13-17.

Chauhan, J.S. 1998. Inheritance of grain weight, size and shape in rainfed rice (Oryza sativa L.). Indian J. Agril. Sci., 68(1): 9-12.

Das \& Bagai, 2000.Aromatic Rice in Bangladesh. In:Aromatic Rice Book.184

Dela Cruz N. and Khush, G.S. 2000. Rice grain quality evaluation procedures. In: Singh, R. K., Singh, U. S. and Khush, G. S. (eds), Aromatic rices. Oxford \& IBH Publishing Co. Pvt. Ltd., New Delhi, India: 16-28..

Islam, M., Rafiqul, B.A.A., Mustafi and Hossain, M. 1996. Socio-economic aspects of fine quality rice cultivation in Bangladesh. Rice Research Prioritization, BRRI / IRRI.

Jorhi Behera, 2007.Vol 6.No 4.348-354.

Juliano, B.O. and Duff, B. 1991. Rice grain quality as an emerging priority in National rice breeding programmes. In: rice grain marketing and quality issues. Los Banos, Laguna, IRRI: 55-64.

Latha, R., Rao, C.S., Subramanian, H.M.S., Eganathan, P. and Swaminathan, M.S. 2004. Approaches to breeding for salinity tolerance a case study on Proterena coarctata. Ann. Appl. Biol. 144(2): 177-184. 
Lefebvre, A., Bassereau, J. F., Pense-Lheritier, A. M., Rivere, C., Harris, N. and Duchamp, R. 2010. Recruitment and training of a sensory expert panel to measure the touch of beverage packages: Issue and methods employed. Food Quality and Preference, 21(1):156-164.

Little, R.R., Hilder, G.B. and Dawson, E.H. 1958. Differential effect of dilute.

Mia, F. 2010. Identification and Differentiation of Aromatic Rice Genotypes Using SSR Markers. M.S.Thesis.Department of Biotechnology. Bangladesh Agricultural University, Mymensingh: 38-44.

Sarker, M.A.H. 2002. Indigenous Fine Aromatic Rice Production: Bangladesh Perspective. 12-15 November 2002. Development of Basic Standard for Organic Rice Cultivation. 1st RDA/ARNOA International Conference. RDA and Dankook Univ. Korea.

Sarker, R.K., Nanda, B.B., Dash, A.B. and Lodhi, S.B. 1994. Grain characteristics and cooking quality of aromatic and non-aromatic, long and slender varieties of rice (Oryza sativa L.). Indian J. Agril. Sci., 64(5): 305-309.

Shangi et al., 2010.Fungal diseases of Aromatic Rice governed by Bangladesh Academy. 34 (2).162-170

Sharma, N.2002. Quality characteristics of non-aromatic and aromatic rice varieties in Punjub. Indian J. Agril. Sci., 72(7): $408-410$.

Siddiq, E.A. 1992. Rice production strategy for the 21st century. Third Dr K Ramish Memorial Lecture, held on 26 August 1992 , at the Orissa University of Agriculture and Technology, Bhubaneshwar.

Singh, R.K., Singh, U.S. and Khush, G.S. 2000. Aromatic Rices. Oxford and IBH Publishing Co. Ltd. New Dellhi. 279p..

Tomar, J.B. and Nanda, J.J. 1985. Genetics and association studies of kernel shape in rice. Indian J. Genet., 45(2): 278-283. 